\title{
Seasonality of Peroxyacetyl nitrate (PAN) in the upper troposphere and lower stratosphere using the MIPAS-E instrument
}

\author{
D. P. Moore and J. J. Remedios \\ Earth Observation Science Group, Department of Physics and Astronomy, University of Leicester, University Road, \\ Leicester, UK
}

Received: 6 August 2009 - Published in Atmos. Chem. Phys. Discuss.: 23 October 2009

Revised: 25 February 2010 - Accepted: 28 May 2010 - Published: 7 July 2010

\begin{abstract}
The Michelson Interferometer for Passive Atmospheric Sounding onboard ENVISAT (MIPAS-E) offers the opportunity to detect and spectrally resolve many atmospheric minor constituents affecting atmospheric chemistry. In this paper, we retrieve global, seasonal PAN volume mixing ratio (vmr) data from MIPAS-E measurements made in January, March, August and October 2003 and present results from this scheme between approximately 300 and $150 \mathrm{hPa}$. The total error on a single PAN retrieval is better than $20 \%$ outside the tropics and better than $50 \%$ in the tropics where uncertainties in water vapor dominate the total error budget. We observe clear differences in the seasonal cycle of PAN in our data, linked closely to biomass burning regions and growing seasons. Highest Northern Hemisphere midlatitude PAN vmrs were observed in August (300-600 pptv on average) compared with the January and October data (less than 250 pptv on average). In the March 2003 data we observe highest PAN vmrs in the tropics with evidence of vmrs between 600 and 1000 pptv over Eastern Asia and over the Central Pacific at $333 \mathrm{hPa}$. The vertical distribution of PAN as a function of latitude (i.e. the zonal mean) highlights the strong inter-annual variability of PAN in the upper troposphere and lower stratosphere (UTLS), most pronounced poleward of $40^{\circ} \mathrm{N}$ (up to $400 \mathrm{pptv}$ over the year). The variability of PAN in the tropical UTLS is also significant and we derive a variability of up to $250 \mathrm{pptv}$ in the averages between January and October 2003. These results represent the first seasonal observations of PAN in the UTLS.
\end{abstract}

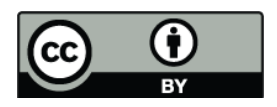

Correspondence to: D. P. Moore (dpm9@le.ac.uk)

\section{Introduction}

Volatile organic compounds (VOCs) play an important role in the chemistry of the troposphere, influencing ozone and hydroxyl radical concentrations and their trends (Jacob, 2003). There have been a reasonable number of in situ measurements (e.g. Singh et al., 2009; Crawford et al., 2003) and remote sensing observations, of these compounds (e.g. Coheur et al., 2007; Glatthor et al., 2007). In this paper we address the ability of the Michelson Interferometer for Passive Atmospheric Sounding onboard ENVISAT (MIPAS-E) to measure peroxyacetyl nitrate $\left(\mathrm{PAN} ; \mathrm{CH}_{3} \mathrm{C}(\mathrm{O}) \mathrm{OONO}_{2}\right)$.

PAN is an important odd-nitrogen compound $\left(\mathrm{NO}_{\mathrm{y}}\right)$ in the atmosphere as it acts as a reservoir of nitrogen oxides $\left(\mathrm{NO}_{\mathrm{x}}=\mathrm{NO}+\mathrm{NO}_{2}\right)$. The long lifetime of PAN at the cold temperatures of the upper troposphere (of the order several weeks (Talukdar et al., 1995)) can allow $\mathrm{NO}_{\mathrm{x}}$ to be sequestered and transported until it is released at lower and warmer altitudes, potentially resulting in ozone production in remote regions (Singh and Hanst, 1981).

Aircraft campaigns studying upper tropospheric chemistry show that PAN is ubiquitous in the mid-to upper troposphere, with peak observed concentrations of 660 pptv (Russo et al., 2003; Pöschl et al., 2001; Roberts et al., 2004). The variability of these compounds suggests that more extensive and regular measurements of VOCs would provide much new information. The increasing use of infra-red spectrometers, such as the MIPAS-E, allows global datasets of VOCs to be compiled if their spectral signatures are detectable.

We extend on previous work by Remedios et al. (2007a) and Allen (2005b) detecting PAN in spectra recorded by the balloon and satellite versions of MIPAS (MIPAS-B and MIPAS-E) to retrieve global PAN concentrations throughout the upper troposphere and lowermost stratosphere and

Published by Copernicus Publications on behalf of the European Geosciences Union. 
evaluate measurements made in January, March, August and October 2003. This paper presents the first analysis of upper troposphere and lower stratosphere PAN measurements made globally in different seasons. To show the consistency of our data with previous measurements, we compare our measurements of PAN with values obtained by Glatthor et al. (2007) during 10 days in October, November and December from MIPAS-E.

\section{MIPAS-E measurements of PAN}

The MIPAS-E instrument was successfully launched onboard the ENVIronmental SATellite (ENVISAT) in March 2002 as part of an ambitious and innovative payload. The ENVISAT is in a polar orbit at an altitude of $800 \mathrm{~km}$, with an orbital period of about 100 minutes and a reference orbit repeat cycle of 35 days. The MIPAS-E (Fischer and Oelhaf, 1996; Fischer et al., 2008) is a Fourier Transform Spectrometer that provides continual limb emission measurements in the mid infrared over the range 685$2410 \mathrm{~cm}^{-1}(14.6-4.15 \mu \mathrm{m})$ at an unapodized resolution of $0.035 \mathrm{~cm}^{-1}$ during the nearly continuous first two years of flight data. Problems with the mirror drive of the interferometer meant that MIPAS initially ceased measurements at the end of March 2004. Operations recommenced in "optimalresolution" in January 2005 at a lower unapodized resolution of $0.0875 \mathrm{~cm}^{-1}$. Measurements from the first period are discussed in this paper. The instrument's field of view is approximately $3 \times 30 \times 400 \mathrm{~km}$ and one complete limb sequence of measurements in nominal mode for the first period consists of 17 spectra with tangent altitudes at $68 \mathrm{~km}, 60 \mathrm{~km}, 52 \mathrm{~km}$, $47 \mathrm{~km}, 42 \mathrm{~km}$ and continuing downwards to $6 \mathrm{~km}$ in $3 \mathrm{~km}$ intervals.

\subsection{Retrieval approach}

PAN exhibits weak, cross-sectional type signatures in the infrared and hence detection and subsequent retrieval is complicated as it relies on the ability to model strong lines from compounds which obscure the target signature. Remedios et al. (2007a) confirm that identifiable features of PAN (band shape and Q branches) can be distinguished remarkably well in MIPAS-B2 data (the balloon-borne version of the MIPAS instrument) by using good laboratory measurements of the spectroscopy of this gas (Allen et al., 2005a,c; Allen, 2005b).

Remedios et al. (2007a) observe the PAN $v_{16} \mathrm{NO}_{2}$ stretch at $794 \mathrm{~cm}^{-1}$ and $v_{10} \mathrm{C}-\mathrm{O}$ stretch at $1163 \mathrm{~cm}^{-1}$ in MIPASB2 spectra (Fig. 5 of their paper). An added complication with PAN is that both spectral ranges suffer from interfering spectral features, with $\mathrm{H}_{2} \mathrm{O}, \mathrm{CO}_{2}$ and $\mathrm{O}_{3}$ present in both windows. Despite these problems, the authors were able to show the presence of PAN in MIPAS-B2 spectra using their detection methodology. The PAN signature was consistent with a volume mixing ratio (vmr) of $260 \mathrm{pptv}$ at $7.5 \mathrm{~km}$ and

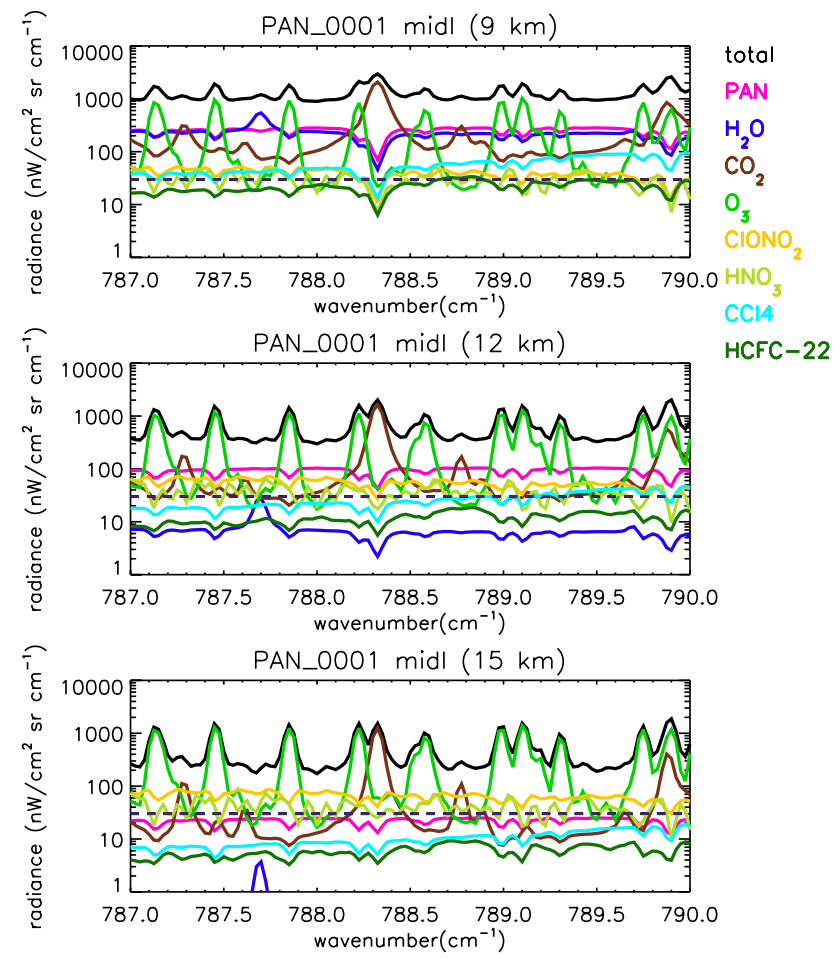

Fig. 1. Modelled radiance contributions in the 787 to $790 \mathrm{~cm}^{-1}$ spectral range in mid-latitudes (20 to 65 degrees). A "typical" MIPAS-E in flight noise equivalent spectral radiance (NESR) of $30 \mathrm{nW} /\left(\mathrm{cm}^{2} \mathrm{srcm}^{-1}\right)$ in band A, Kleinert et al. (2007), is represented by the black dashed line.

$180 \mathrm{pptv}$ at $10.4 \mathrm{~km}$. The spectral range coverage of MIPASE extends over both of these bands potentially allowing observation of PAN in the spaceborne version of MIPAS.

Figure 1 shows the calculated contribution of PAN to the limb radiance between $787-790 \mathrm{~cm}^{-1}$ (a reduced range compared to the entire $v_{16} \mathrm{NO}_{2}$ stretch) at 9,12 and $15 \mathrm{~km}$ in the mid-latitudes, as calculated using the Oxford reference forward model (RFM). The RFM is a line-by-line radiative transfer model, derived from the Genln 2 model (Edwards, 1992), with the ability to simulate infra-red spectra given the calculated or measured instrument field-of-view, lineshapes, spectroscopic parameters and atmospheric climatology profiles (see http://www.atm.ox.ac.uk/RFM/ for further details). This range was chosen as it represents a spectral region where strong PAN emission features are present and the interference from other gases is smallest. The retrieval of PAN volume mixing ratios from MIPAS-E spectra used four microwindows in this spectral range (MW1: $787.550 \mathrm{~cm}^{-1}$ to $787.750 \mathrm{~cm}^{-1}$, MW2: $787.925 \mathrm{~cm}^{-1}$ to $788.125 \mathrm{~cm}^{-1}$, MW3: $788.675 \mathrm{~cm}^{-1}$ to $788.875 \mathrm{~cm}^{-1}$ and MW4: $789.375 \mathrm{~cm}^{-1}$ to $789.700 \mathrm{~cm}^{-1}$ ). Profiles for pressure, temperature and all interfering gases, except PAN, were taken from the version 3.1 mid-latitude day reference 
atmospheres of Remedios et al. (2007b). The PAN profiles used in this simulation was taken from the MOZART model (Hauglustaine et al., 1998) for mid-July in the Eastern United States of America.

Reference spectra were calculated at a spectral resolution of $0.035 \mathrm{~cm}^{-1}$ and a spectral sampling of $0.025 \mathrm{~cm}^{-1}$ including PAN and all the other emitters in the region. To remove saturation effects, a second spectrum was calculated at the same resolution with all gases except PAN. Differencing these two spectra leaves the radiance contribution from PAN alone. The same method was used to determine the radiance contribution from each of the other interfering gases; the contaminants for PAN were $\mathrm{H}_{2} \mathrm{O}, \mathrm{CO}_{2}, \mathrm{O}_{3}, \mathrm{CCl}_{4}, \mathrm{HNO}_{3}$, $\mathrm{ClONO}_{2}, \mathrm{COF}_{2}, \mathrm{HCFC}-22$ and $\mathrm{NH}_{3}$. From these simulations, the PAN signal at a single spectral point is expected to exceed the MIPAS-E noise equivalent spectral radiance (NESR) and the signal of other contaminants at $9 \mathrm{~km}$ and $12 \mathrm{~km}$, based on our climatology vmr estimate of $223 \mathrm{pptv}$ and 131 pptv respectively.

The retrievals of PAN vmrs from MIPAS-E data have been achieved using the MIPAS Orbital Retrieval using Sequential Estimation (MORSE), a FORTRAN77 program developed by the University of Oxford (http://www.atm.ox.ac.uk/MORSE/) to allow groups to retrieve atmospheric profiles from MIPAS spectra. In essence, the scheme uses a sequential estimation approach to determine the most probable solution consistent with both the measurements and the a priori information.

The MIPAS-E instrument makes $m$ radiance measurements at different limb altitudes. A set of $n$ parameters (the state vector $\boldsymbol{x}$ ) are determined from this set of measurements $(\boldsymbol{y})$. The aim of the retrieval is to gain as much information about $\boldsymbol{x}$ given $\boldsymbol{y}$. The standard optimal estimation approach (Rodgers, 2000) provides a linearized form for an estimate of $\hat{\boldsymbol{x}}$ (the atmospheric profile) that is based on a prior estimate $\boldsymbol{x}_{a}$ of the state and the set of measurements from the instrument:

$\hat{\boldsymbol{x}}=\mathbf{G y}+\left(\mathbf{I}_{n}-\mathbf{G K}\right) \boldsymbol{x}_{a}$

where $\mathbf{K}$ is the Jacobian matrix $\left(\mathbf{K}_{i, j}=\partial y_{i} / \partial x_{j}\right)$ and $\mathbf{G}$ is the gain matrix given by:

$\mathbf{G}=\mathbf{S}_{a} \mathbf{K}^{T}\left(\mathbf{S}_{y}+\mathbf{K} \mathbf{S}_{a} \mathbf{K}^{T}\right)^{-1}$

$\mathbf{S}_{a}$ is the covariance of $\boldsymbol{x}_{a}$ about the exact state, which was set at $300 \%$ for PAN, and $\mathbf{S}_{y}$ the covariance of $\boldsymbol{y}$ about the perfect measurements that would arise from the exact state. For $\mathbf{S}_{a}$, the off-diagonal elements were determined by a first order auto-regressive model with a vertical correlation length of $6 \mathrm{~km}$. The off-diagonal elements of $\mathbf{S}_{y}$ were set to zero (assuming no noise correlation between different altitudes).

If the problem is not too non-linear, then the LevenbergMarquardt iteration technique can be used to find the best estimate of the state, $\hat{\boldsymbol{x}}$. The matrices $\mathbf{S}_{a}$ and $\mathbf{S}_{y}$ are inverted using the Gauss-Jordan Elimination technique with full-pivoting, based on the routine GAUSSJ given on pages 28-29 of Numerical Recipes (Press et al., 1992)

$$
\begin{aligned}
\boldsymbol{x}_{i+1}= & \boldsymbol{x}_{i}+\left[(1+\gamma) \mathbf{S}_{a}^{-1}+\mathbf{K}_{i}^{T} \mathbf{S}_{y}^{-1} \mathbf{K}_{i}\right]^{-1} \\
& \left\{\mathbf{K}_{i}^{T} \mathbf{S}_{y}^{-1}\left[\mathbf{y}-\mathbf{F}\left(\boldsymbol{x}_{i}\right)\right]-\mathbf{S}_{a}^{-1}\left[\boldsymbol{x}_{i}-\boldsymbol{x}_{a}\right]\right\}
\end{aligned}
$$

where $\mathbf{F}$ is the RFM modelled radiance at instrument spectral resolution with vertical field-of-view convolution.

In the case where the error covariance is diagonal, then an economy in the retrieval can be gained by updating the state estimate sequentially, as is performed by MORSE, updating one measurement at a time. This replaces the matrix inverse in Eq (3). by a scalar reciprocal. As some measurements are likely to be more linearly related to the state vector than others, the advantage of this approach is that the intermediate state will be closer to the final solution and so fewer iterations may be needed. MORSE uses the full retrieval state vector right from the start, with the measurements incorporated sequentially rather than with one large matrix. Since measurements are assumed uncorrelated between different tangent heights or different microwindows, mathematically the solution should be the same as if all measurements were used at once. The linear algebra may also be computationally faster as a matrix inversion is no longer involved.

The value of $\gamma$ in Eq. (3), is initialised to a small value of one. If the value obtained from the iteration reduces the chisquare parameter, the new estimate, $\boldsymbol{x}_{i+1}$, is accepted and $\gamma$ is divided by ten. If the error increases on $\boldsymbol{x}_{i+1}$ however, then $\gamma$ is multiplied by ten and Eq. (3) is solved again until an increment is obtained that reduces the chi-square below a threshold of 1.5 and the difference between consecutive chisquare values is less than 0.1 . In our successful retrievals, the scheme generally converges within 2 to 3 iterations.

Clouds were detected using a simple ratio approach by computing a ratio between the mean radiance in the $788.20 \mathrm{~cm}^{-1}$ to $796.25 \mathrm{~cm}^{-1}$ and $832.30 \mathrm{~cm}^{-1}$ to $834.40 \mathrm{~cm}^{-1}$ spectral bands (Spang et al., 2004), with a threshold of 4 in band $A$ to exclude thin cloud cases. If ratios below this value were found in a profile, the measurement at this altitude and all altitudes below was flagged as cloudy, no retrieval performed on the scan and the scheme then analyses the next gas and/or scan.

Before the PAN retrievals are performed, we use MORSE to retrieve pressure and temperature (jointly) as well as water vapour, ozone, nitric acid, methane, nitrous oxide, carbon tetrachloride and chlorine nitrate volume mixing ratios, in that order. PAN is then jointly retrieved with water vapour continuum. The a priori PAN vmr information was taken from mid-latitude values for tropospheric mid-latitude calculations (Hauglustaine et al., 1998) with an assumed uncertainty of $300 \%$ on the profile. Spectroscopic data were taken from measurements by Allen (2005b) for PAN. All other spectroscopic data were taken from HITRAN 2004 

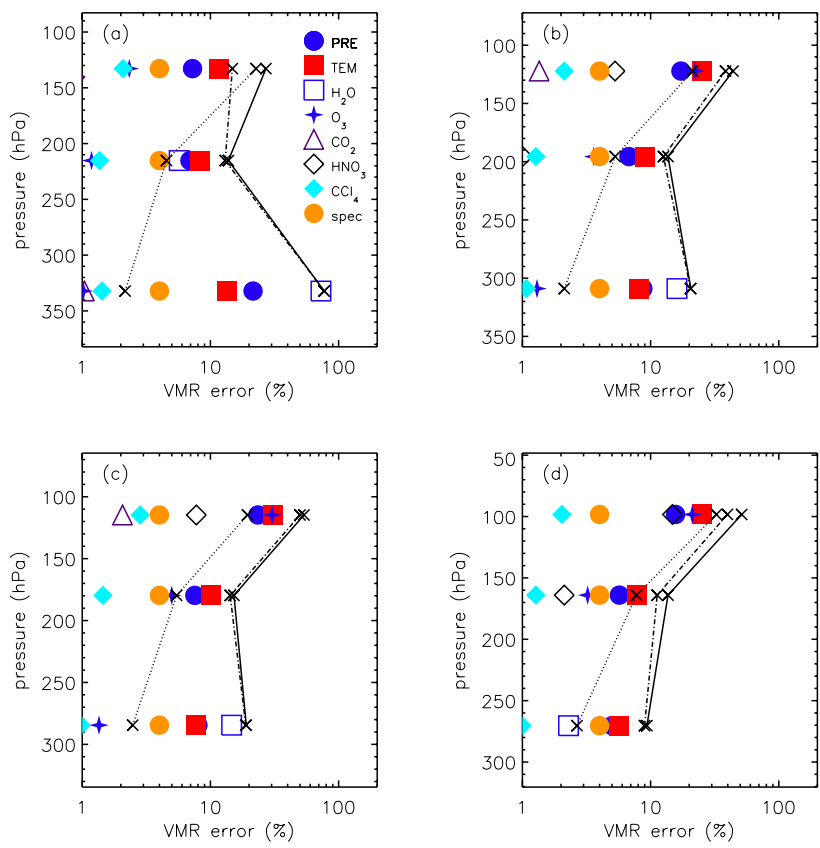

Fig. 2. Error budget for PAN vmr retrievals. The data have been split into regimes, (a) $20^{\circ} \mathrm{S}-20^{\circ} \mathrm{N}$ - tropical, (b) $20^{\circ}-65^{\circ}-$ midlatitudes, (c) $65^{\circ}-90^{\circ}$ in the summer hemisphere - polar summer, (d) $65^{\circ}-90^{\circ}$ in the winter hemisphere - polar winter. The solid black line represents the total error on a single retrieval. The random (dotted) and systematic (dashed) component of the error are also shown. Systematic errors are dominated by pressure ("PRE") and temperature ("TEM"), PAN spectroscopy ("SPEC"), and gain uncertainties.

(Rothman et al., 2005) with updates between 2004 and 2008 applied.

\subsection{Retrieval errors}

A detailed error analysis for PAN is shown in Fig. 2 for four separate latitude bands - tropical $\left(20^{\circ} \mathrm{S}-20^{\circ} \mathrm{N}\right)$, mid-latitudes $\left(20^{\circ}-65^{\circ}\right.$ in each Hemisphere), polar summer $\left(65^{\circ}-90^{\circ}\right.$ in the summer Hemisphere) and polar winter $\left(65^{\circ}-90^{\circ}\right.$ in the winter Hemisphere). We show both random (retrieval noise) and systematic (model parameter error, gain, instrument line shape and spectroscopy) error components along with the total error.

The MORSE scheme was designed to to be able to replicate and improve upon the retrieved parameters by the European Space agency operational processor (Raspollini et al., 2006). In this study we assume that MORSE is performing as well as the operational processor and hence we use some parameter uncertainties based upon validated data from the operational processor. We believe that our error estimates therefore represent an upper limit to the total error.

Firstly, the systematic model parameter errors were calculated using measured biases in MIPAS-E data. An uncer- tainty of $20 \%$ has been indicated for MIPAS-E water vapour (Lahoz et al., 2004), 10\% for ozone (Cortesi et al., 2007) and $15 \%$ for nitric acid (Wetzel et al., 2007). Uncertainties of $1 \mathrm{~K}$ for temperature (Ridolfi et al., 2007) and $4 \%$ for pressure (Raspollini et al., 2006) were used. The error for the other contaminants was expected to be small; we assumed a $10 \%$ uncertainty for each of them. The errors due to uncertainties in these gases were likely to be lower in the real measurements than calculated here. The uncertainty of the instrument gain and instrument offset were taken to be $2 \%$ and $2 \mathrm{nW} /\left(\mathrm{cm}^{2} \mathrm{srcm}^{-1}\right)$ respectively (Spang et al., 2005). Spectroscopic inaccuracies of PAN cross-section data were set to $4 \%$ based on the PAN $794 \mathrm{~cm}^{-1}$ band work of Allen et al. (2005a); this may be an underestimate of the error at temperatures less than $250 \mathrm{~K}$. We recognise that in retrieved monthly mean temperature fields for January, March, August and October 2003 (not shown), tropical tropopause values ranged between 180 and $200 \mathrm{~K}$ (at $100 \mathrm{hPa}$ ). Assuming a linear relationship between the reported spectroscopic errors reported in Allen et al. (2005c) and temperature, the expected spectroscopic error is calculated not to exceed 5.2\%, even at the very coldest tropopause temperatures we measure of around $180 \mathrm{~K}$. The total error on a single retrieved $\mathrm{vmr}$ is calculated to be mainly below $50 \%$ at pressures above $100 \mathrm{hPa}$, and in the "best case" better than $20 \%$. Systematic errors are mainly dominated by the water vapour uncertainty propagating into the retrieved vmrs, although pressure and temperature uncertainties also contribute around $10 \%$ to the total error.

\subsection{Retrieval characterisation}

To characterise the data quality from a single profile retrieval we can use the averaging kernel, information content and the degrees of freedom for signal (dfs) of the measurement (Rodgers, 2000). Figure 3 shows an example of an averaging kernel for a Northern Hemisphere mid-latitude retrieval in August 2003 (from 4 August 2003, $41^{\circ} \mathrm{N}, 91^{\circ} \mathrm{W}$ ) at pressure greater than $100 \mathrm{hPa}$. Although very sensitive to the concentration of PAN, the PAN averaging kernels generally peak above 0.4 in the upper troposphere. As PAN mixing ratios decrease rapidly with increasing altitude, particularly so in the stratosphere, the corresponding averaging kernels rapidly tend to zero. The area of the $539 \mathrm{hPa}, 389 \mathrm{hPa}$ and $261 \mathrm{hPa}$ levels is between 0.8 and unity, indicating the retrieval results are almost free of a priori bias. Looking at the width of the averaging kernels in fig. 3 we can determine a vertical resolution of between 3 and $4 \mathrm{~km}$ in altitude terms between $100 \mathrm{hPa}$ and $450 \mathrm{hPa}$. For the chosen profile the degrees of freedom for signal is 2.7 for these 4 levels; this can vary between 0.5 and 3.8 (when taking 4 measurement levels in the $100 \mathrm{hPa}$ and $450 \mathrm{hPa}$ range) and is heavily dependent on the mixing ratio of PAN in the upper troposphere. 


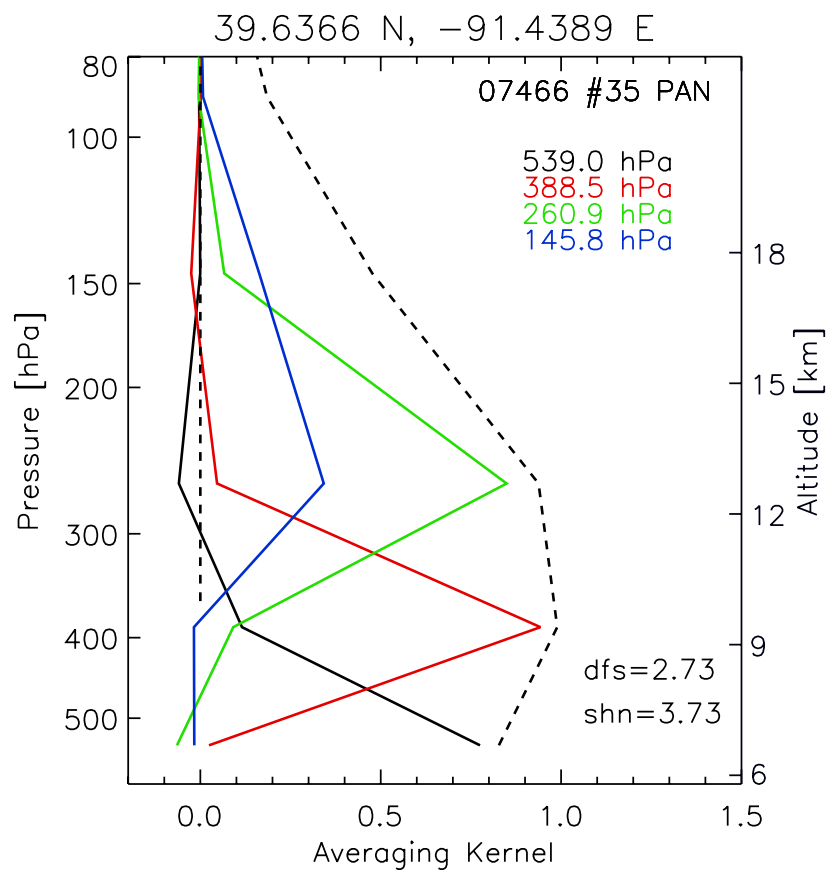

Fig. 3. a representative averaging kernel for a single mid-latitude PAN retrieval from orbit 07466, scan number 35 (from 4 August $2003,41^{\circ} \mathrm{N}, 91^{\circ} \mathrm{W}$ ). There are $\sim 2.7$ degrees of freedom (dfs) for these measurements. The measurements also have 3.7 bits of shannon information content (shn). The dashed black line represents the sum of the rows of the averaging kernel at each tangent altitude.

\section{Results}

\subsection{PAN sensitivity in MIPAS-E spectra}

We firstly present an example of an averaging kernel showing that the MIPAS-E spectral measurements are sensitive to changes in PAN vmr in the upper troposphere in the midlatitudes. In this section, we take examples of PAN retrievals with a variety of volume mixing ratios and investigate whether measured MIPAS-E spectra can be fitted as well by including or neglecting PAN. This approach follows that of Glatthor et al. (2007) who checked whether, using their retrieved PAN amounts, the measured MIPAS spectra can be modelled just as well by complete neglect of PAN. Their residuals clearly showed that the residual fit was better including retrieved PAN and that the RMS deviation between measured and modelled spectra reduced by $35 \%$ at $13 \mathrm{~km}$ $(220 \mathrm{hPa})$.

From orbit 07466 on 4 August 2003, we show the quality of the residual fit for a variety of retrieved PAN vmrs (Fig. 4). It can be seen (Fig. 4a-c) that the residual fit without PAN included in the simulation is up to $200 \mathrm{nW} /\left(\mathrm{cm}^{2} \mathrm{sr} \mathrm{cm}^{-1}\right)$ away from the measured radiance. With retrieved PAN (and continuum) included, the residual is comfortably within 3 sigma of the average MIPAS-E noise of $30 \mathrm{nW} /\left(\mathrm{cm}^{2} \mathrm{srcm}^{-1}\right)$ re-
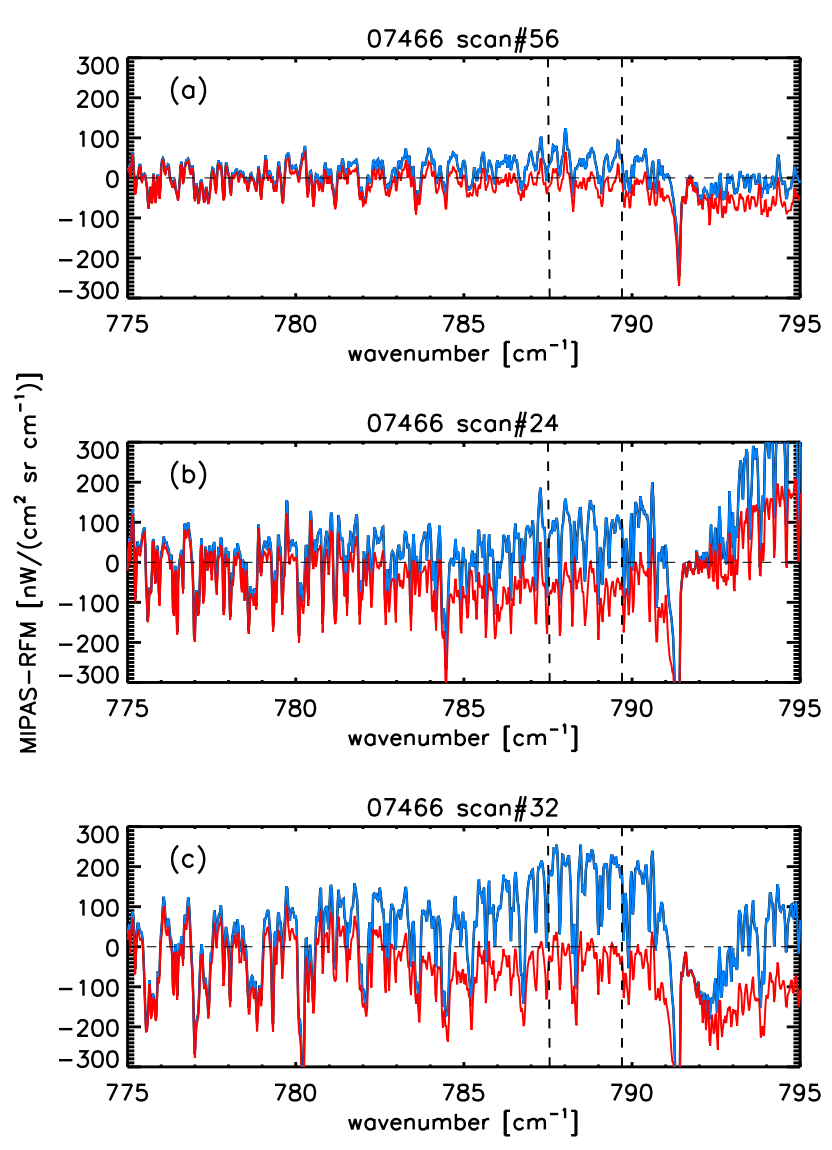

Fig. 4. Examples of MIPAS-E radiance - RFM modelled radiance resiuduals for orbit 07466 on 4 August 2003 at the nominal $12 \mathrm{~km}$ altitude level. Scenes were chosen which represent the typical behaviour of (a) low PAN levels below the median vmr for August 2003 of 119 ppt (this case has a vmr of 106 ppt). Case (b) represents a slightly enhanced retrieved PAN vmr of $164 \mathrm{ppt}$ and (c) shows a moderately enhanced case of $379 \mathrm{ppt}$. The blue line is the fit in each case without considering retrieved PAN and the red line is the fit including retrieved PAN (and continuum). The vertical black dashed lines show the range in which the four PAN microwindows were chosen. The co-ordinates of the MIPAS-E measurements shown are (a) $63^{\circ} \mathrm{N}, 105^{\circ} \mathrm{W}$, (b) $85^{\circ} \mathrm{N}, 80^{\circ} \mathrm{E}$ and (c) $56^{\circ} \mathrm{N}, 90^{\circ} \mathrm{W}$.

ported by Kleinert et al. (2007) in all three cases. As expected, the fit without PAN is worse when considering the more enhanced PAN cases. We also look at the correlation (not shown) between retrieved $\mathrm{CCl}_{4}$ and PAN both globally and regionally and see no correlation between the results suggesting that we are fitting PAN and not a $\mathrm{CCl}_{4}$ feature. Taking the residuals from each microwindow of each scan for August 2003 at an average pressure of $185 \mathrm{hPa}$ (measurement level 15 of 17 of MIPAS-E), Fig. 5, we observe a normal distribution to the residuals themselves suggesting that the microwindow chosen has no bias due to ill-fitting of other contaminants. 


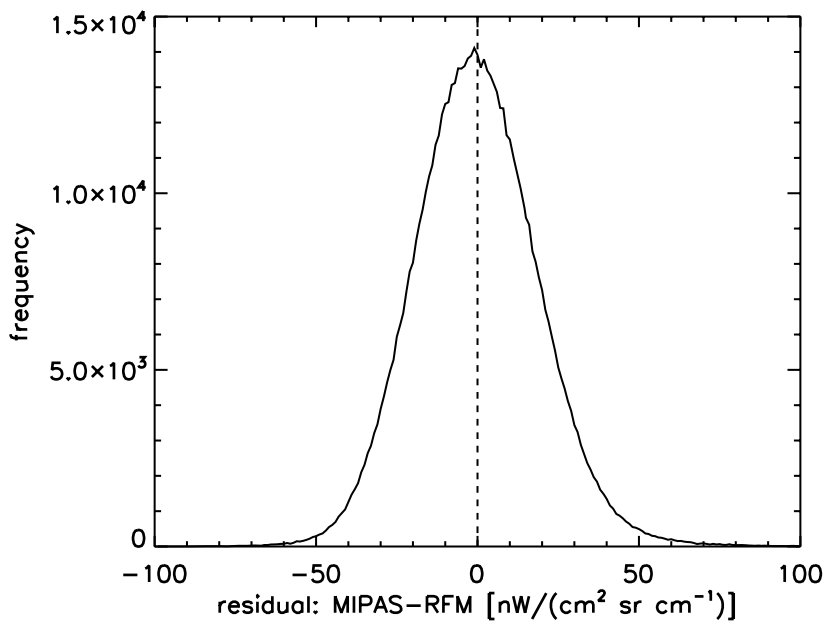

Fig. 5. A histogram of residuals (MIPAS-E measurements-RFM modelled radiances) from 15662 scans from August 2003 at approximately $185 \mathrm{hPa}$. The standard deviation of our residuals is $19 \mathrm{nW} /\left(\mathrm{cm}^{2} \mathrm{srcm}^{-1}\right)$. Note that the noise equivalent spectral radiance in band A of the MIPAS-E is below $25 \mathrm{nW} /\left(\mathrm{cm}^{2} \mathrm{sr} \mathrm{cm}^{-1}\right)$ at $800 \mathrm{~cm}^{-1}$, (Kleinert et al., 2007). The dashed line represents the zero point in the residual.

\subsection{Seasonality of PAN global distributions}

To investigate the seasonality of PAN volume mixing ratios (vmrs) in the upper troposphere and lower stratosphere (UTLS) data have been chosen from four months in 2003 (January, March, August and October) therefore covering all seasons. In addition to this we wished to look at different regimes within the data. The January period covers the biomass burning season in sub-Saharan Africa, March is at the beginning of the Northern Hemisphere growing season and there are strong biomass burning events recorded over Central America, Central Africa and South-East Asia. August encapsulates the South American and Central African biomass burning season and also one of the main months of the Northern Hemisphere growing season. By October, there is still strong burning over Southern America but the region of major biomass burning moves eastward to East Central Africa and Madagascar with major fire events also over Northern Australia.

One caveat of our analysis approach that should be noted here, is that we decided against interpolation of the data onto identical pressure levels. We found that (not shown) as PAN vmrs decrease very rapidly with altitude, particularly close to the tropopause, interpolation is likely to introduce features which are not present in the dataset. In addition, we usually obtain a maximum of three independent pieces of information from our eight vertical measurements and interpolation will increase the effective smoothing of the data. This does mean that although we compare the same nominal measure-
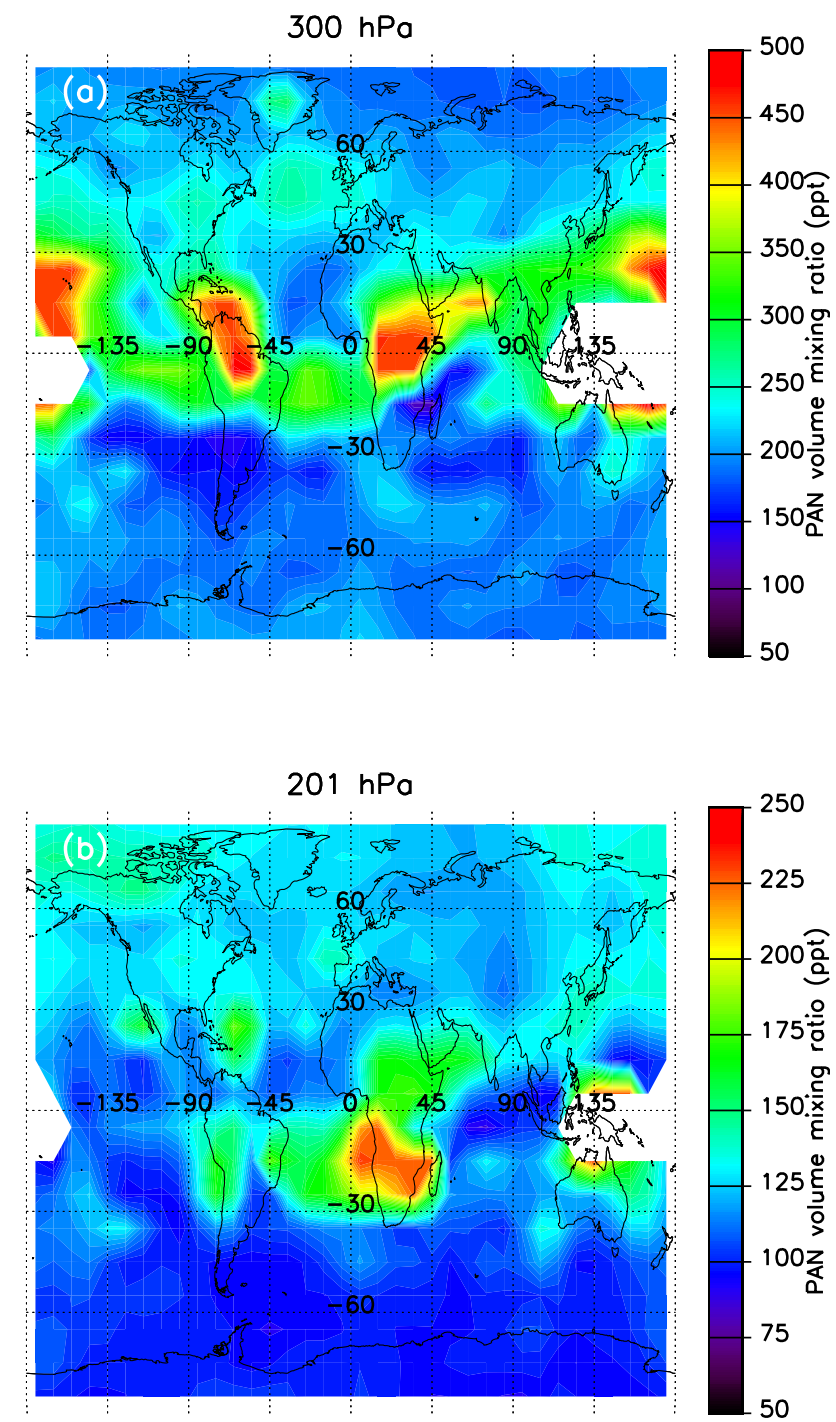

Fig. 6. Global PAN distributions (in units of ppt) at average pressure levels of $300 \mathrm{hPa}$ (a) and $201 \mathrm{hPa}$ (b) averaged for the month of January 2003. White areas are cloud contaminated regions.

ment level, the average pressure is slightly different between different months. We feel that this does not limit the approach but makes the analysis less biased than it otherwise could be.

In January 2003, Fig. 6, a map of PAN distributions is derived from 390 orbits of MIPAS-E data plotted at average pressure levels. The data are contoured and gridded at 20 degree longitude and 10 degree latitude resolution. The white regions in Fig. 6 (and Figs. 7-9) are regions that have zero data due to high cloud contamination. We decided that to reduce the effect of creating biases due to few data points, to remove all regions containing less than 5 data points. What we see at $300 \mathrm{hPa}$ in Fig. 6a is a distinct "band" of PAN volume mixing ratios (vmrs) above $300 \mathrm{pptv}$ which appear to 

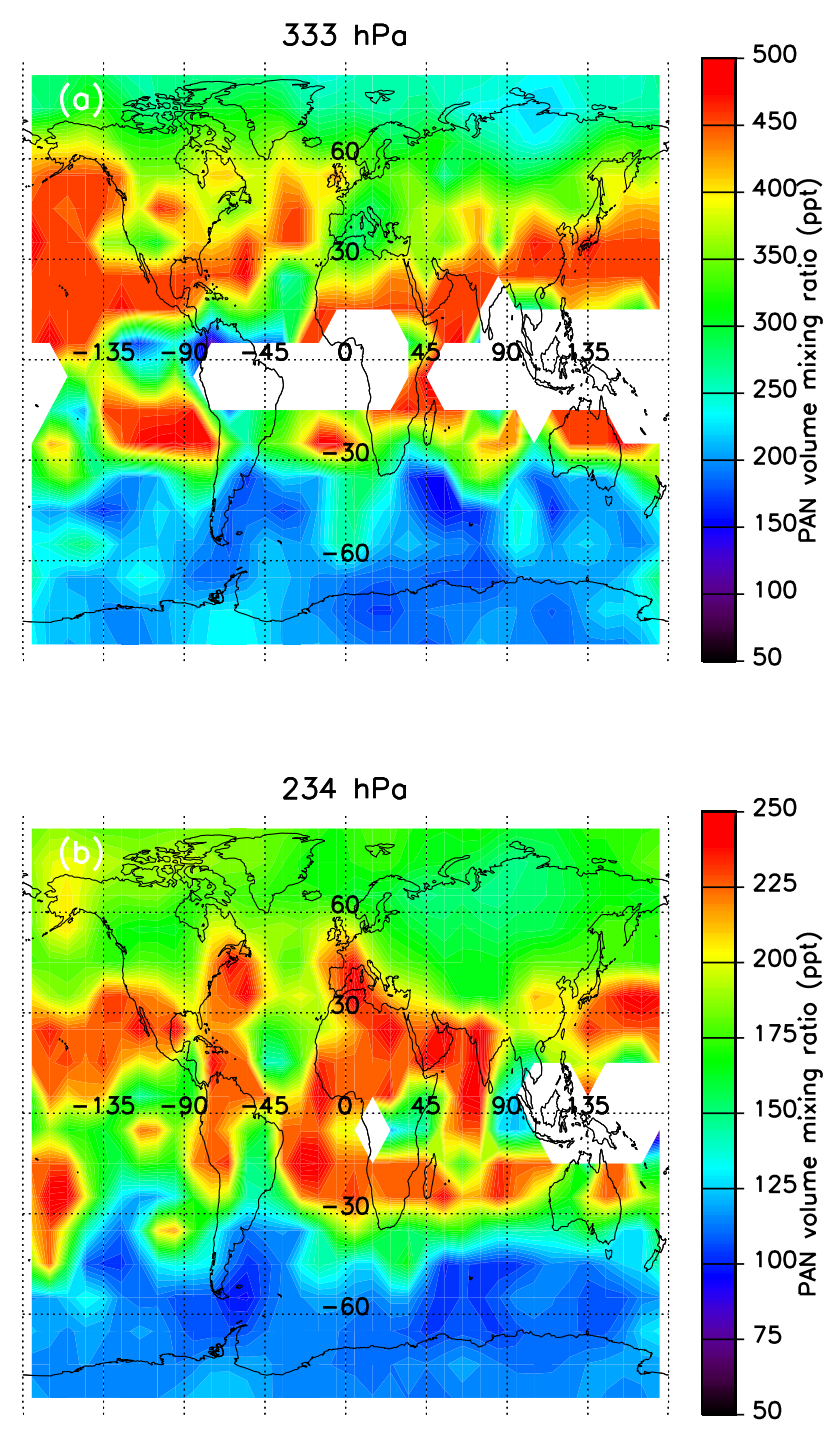

Fig. 7. Global PAN distributions (in units of ppt) at average pressure levels of $333 \mathrm{hPa}$ (a) and $234 \mathrm{hPa}$ (b) averaged for the month of March 2003. White areas are cloud contaminated regions.

be linked closely to the Central African and Northern Amazon regions. The data clearly show inter-continental transport between Africa and Southern America. What is particularly interesting is the high PAN of up to 600 pptv over the Central Pacific Ocean which may have originated from Eastern Asia. We see weak differences at this level between the Northern Hemisphere and Southern Hemisphere data in the mid-latitudes. At $201 \mathrm{hPa}$, there is a clear peak in the PAN vmrs of greater than 150 pptv over Central Africa extending up towards the Middle East region combined with westward transport from Central Africa out over the Southern Atlantic Ocean. Although we have high cloud contamination over the western Pacific Ocean, there is also possible enhancement of PAN in the region which may be related to biomass burning.
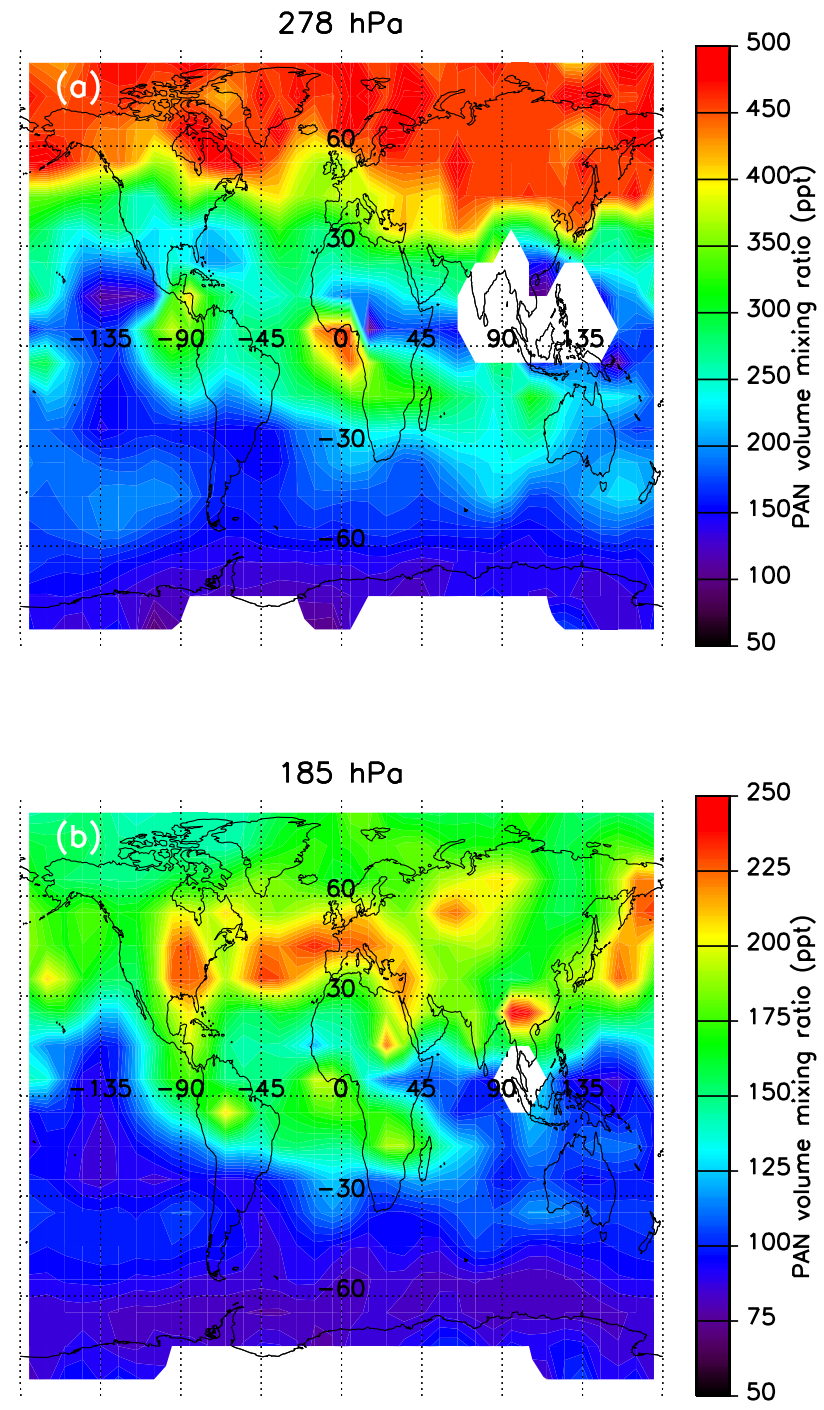

Fig. 8. Global PAN distributions (in units of pptv) at average pressure levels of $278 \mathrm{hPa}$ (a) and $185 \mathrm{hPa}$ (b) averaged for the month of August 2003. White areas are cloud contaminated regions.

By March 2003, Fig. 7, the highest vmrs in the monthly average from 319 orbits were centred around the tropics (up to $600 \mathrm{pptv}$ in the monthly average at $333 \mathrm{hPa}$ ) and South-East Asia extending into the Central and Eastern Pacific Ocean. Over Europe we see up to a $50 \%$ increase in PAN at this level and values for continental North America increase by up to $100 \%$ from January 2003. The volume mixing ratios over the Southern Ocean remain largely unchanged. At the $234 \mathrm{hPa}$ level we see significant changes over many regions from January observations. The high vmrs observed over Central-Southern Africa remain extending into the Southern Atlantic Ocean and further North over the Sahara, Middle East and Southernmost Europe. PAN vmrs increase by up to $100 \%$ over Eastern Asia and transport from this region may 


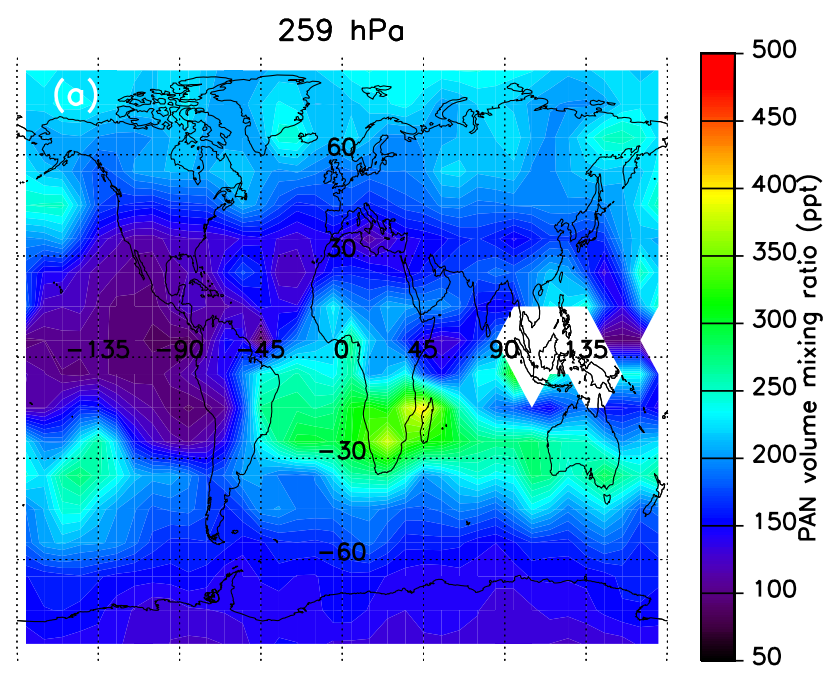

$172 \mathrm{hPa}$

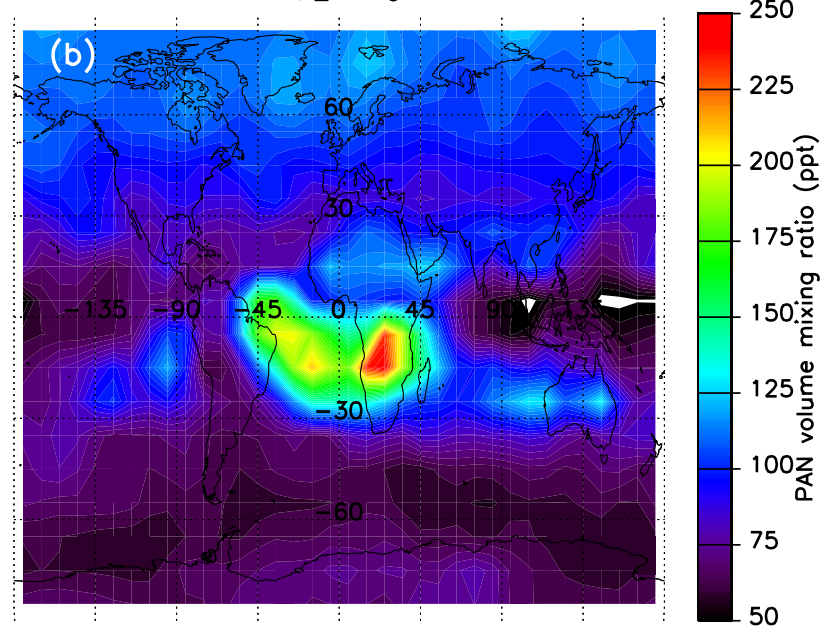

Fig. 9. Global PAN distributions (in units of pptv) at average pressure levels of $259 \mathrm{hPa}$ (a) and $172 \mathrm{hPa}$ (b) averaged for the month of October 2003. White areas are cloud contaminated regions.

explain the large increase of PAN vmrs over the Northern Pacific Ocean. The increase over the Southern Pacific Ocean is more difficult to assign although it appears that there is a general increase across all Southern Hemisphere mid-latitudes.

For our August 2003 analyses, we utilise data from 396 orbits covering the whole month. In Fig. 8a, the same retrieval level as in Fig. 6a, we now see that there is a distinctly stronger hemispheric difference in the PAN dataset compared with January and March 2003, with the largest PAN vmrs of over 500 pptv found over Western Siberia. Although we are not able to look directly at sources of PAN using the MIPAS-E we speculate that the largest vmrs of PAN may be closely linked to deciduous forests with a con- tribution of both Siberia with deciduous needle forests and Eastern America with deciduous broadleaf forests. It has been shown by Min and Wildt (2002) that under a constant light intensity, acetone emission rates increase exponentially with leaf temperature. When leaf temperature is kept constant, acetone emission increases with light intensity. The photolysis of acetone produces the peroxyacetyl radical and, in the presence of nitrogen dioxide, the reversible reaction of the peroxyacetyl radical with nitrogen dioxide produces PAN. It is possible, therefore, that the enhancement of PAN over Western Siberia may be linked with enhanced acetone vmrs. We cannot, however, rule out the fact that long-range transport might be causing, or contribute to the elevated PAN vmrs. We still clearly see that Africa and Southern America are still indirect sources of PAN although the measured vmrs are lower than we see over Siberia and North-East Asia.

The 367 orbits from October 2003 show a seasonal progression and our results are similar to the findings of Glatthor et al. (2007). The highest PAN vmrs are linked to Southern Hemisphere biomass burning regions (highest over Central Africa) with the $259 \mathrm{hPa}$ data showing long-range transport over the Southern Atlantic and the Southern Ocean towards Australia. At the $259 \mathrm{hPa}$ average pressure level we also see an indication that there is a PAN enhancement at Northern Hemisphere mid- to high latitudes. October is towards the end of the Northern Hemisphere growing season so what we see could be the result of the slow decay of the summer PAN maximum at these latitudes. The $172 \mathrm{hPa}$ data still have a small Hemispheric difference, but the most notable PAN enhancement is throughout the Central African region and Southern Atlantic Ocean.

From these data, it is noticeable that the seasonal variation of PAN is pronounced with the most variability in the Northern Hemisphere mid- to high latitudes and is perhaps linked more to variations in plant activity rather than industrial activity. The area over Central Africa region acts as a quasipermanent reservoir of PAN throughout the year with small seasonal variability of PAN and a small seasonal North-South shift with the change in season, intrinsically linked to the change in biomass burning regions.

In Fig. 10 we look at monthly zonal means of PAN and how this varies for each month. We also overplot the $+/-2$ PVU (potential vorticity unit - units of $10^{-6} \mathrm{~K} \mathrm{~m}^{2} \mathrm{~kg}^{-1} \mathrm{~s}^{-1}$ ) level which approximates the tropopause outside the tropics (Holton et al., 1995). In the same review of stratosphere-troposphere exchange, the authors also describe the region between the $+/-2 \mathrm{PVU}$ level and the $380 \mathrm{~K}$ theta level as denoting the lowermost stratosphere, whose isentropic surfaces span the tropopause. At around $10^{\circ} \mathrm{S}$, we see penetration of PAN through the tropopause which is most likely associated with the African biomass burning events. By March 2003 (Fig. 10b) we observe an increase of around $200 \mathrm{ppt}$ in the average UT PAN in the Northern Hemisphere compared to January of the same year, with an increase also in the tropics. This contrasts with 

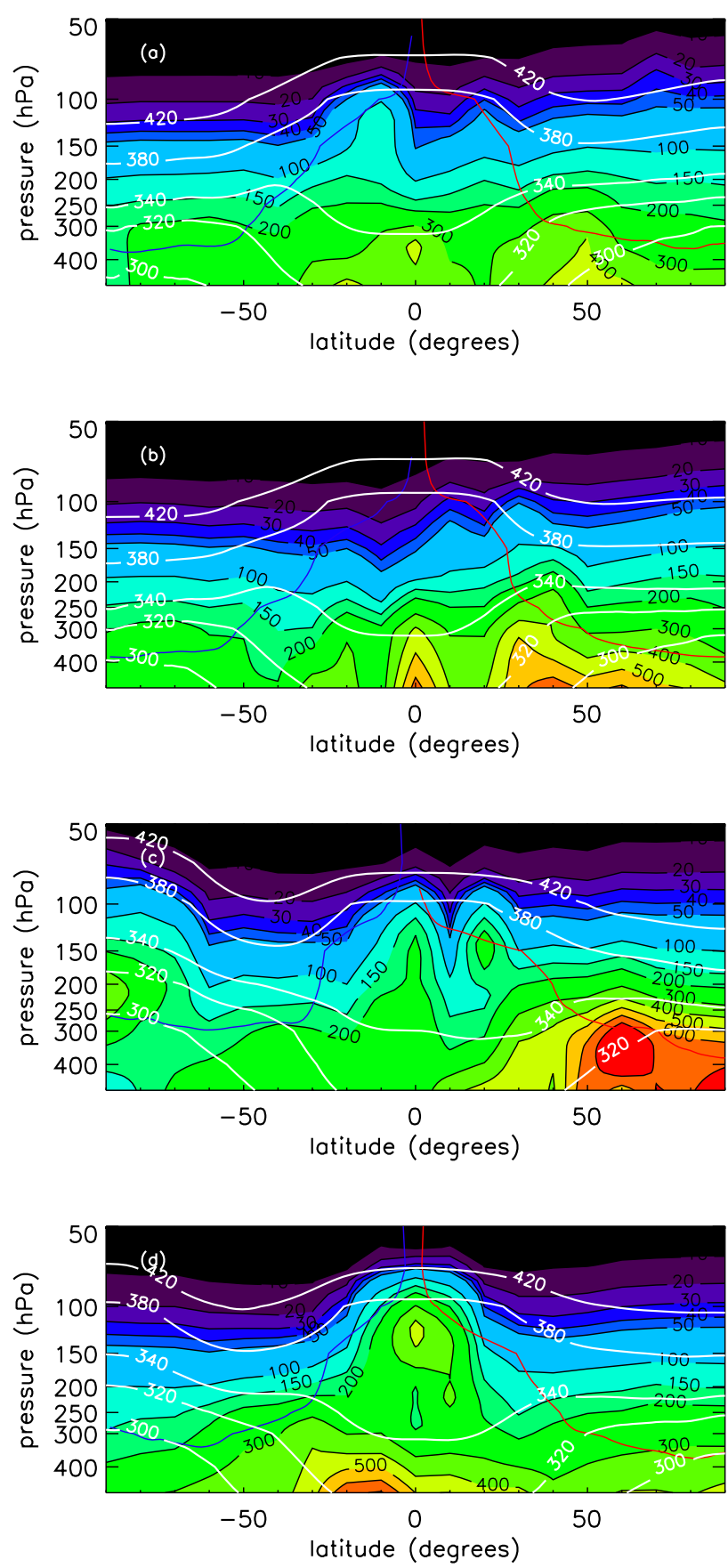

Fig. 10. Seasonal latitudinal PAN distribution (units of pptv), averaged zonally for (a) January 2003, (b) March 2003, (c) August 2003 and (d) October 2003. The white lines indicate theta levels (K) and the red and blue lines represent the $+/-2$ PVU levels

the Southern Hemisphere observations which remain relatively similar to January 2003.

The August 2003 cross-section (Fig. 10c) exhibits clear differences between the Northern and Southern hemisphere, with a pool of high PAN with average vmrs greater than
600 pptv extending from 50 to $90^{\circ} \mathrm{N}$ in the uppermost troposphere. We also see evidence of higher PAN in the lower stratosphere with vmrs greater than 300 pptv. We also see a bimodal effect in the tropics, with two regions of biomass burning at 0 and $20^{\circ} \mathrm{N}$ intersected by lower PAN (less than $100 \mathrm{pptv})$ at $10^{\circ} \mathrm{N}$. A pool of PAN with vmrs between $200 \mathrm{pptv}$ and $400 \mathrm{pptv}$ is found poleward of $70^{\circ} \mathrm{S}$ between the -2 PVU surface and the $340 \mathrm{~K}$ level. We do not show the plot here, but the retrieved temperature poleward of $70^{\circ}$ in this region is less than $205 \mathrm{~K}$ in the monthly average. What we may have here is evidence of the isolation of a PAN injection into the lower stratosphere from either June or July 2003 and the cold temperatures, allowing the transportation of the PAN to polar latitudes.

By October 2003, we retrieve the highest values of PAN in the tropical upper troposphere of any of the months used in this study (300-500 pptv). There is no evidence of a split between hemispheres as was observed in August 2003 and the strong PAN feature is most likely driven by Central African biomass burning which is seen mainly between $10-20^{\circ} \mathrm{S}$. We also no longer see PAN vmrs exceeding 400 pptv in the Northern Hemisphere as was observed in the August 2003 data.

We have checked on a qualitative basis, whether the tropical and subtropical PAN distribution could be caused by biomass burning. By using the fire counts from the Moderate Resolution Imaging Spectroradiometer (MODIS) experiment on the Terra satellite we see that the January fire counts are highest over sub-Saharan Africa, the Northern Amazon and South-East Asian region, closely linked to highest observed PAN. In August, the highest number of fire counts are in Central-Southern Africa where we observe highest tropical values. By October, the highest fire counts move to South-East Africa and North-East Brazil, coincident with the highest tropical PAN vmrs. In future work we will look to correlate these PAN data with a potential tracer of biomass burning, $\mathrm{C}_{2} \mathrm{H}_{2}$, to see whether biomass burning is the only source of PAN in the tropics.

The work of Glatthor et al. (2007) investigated the PAN amount differences observed both in and out of the Southern Hemisphere PAN plume in October to December. Choosing an area containing the Southern Hemisphere plume (between South America, across Africa, towards Australia) they contrasted this with the PAN amounts above the less polluted Central and Eastern Pacific. Although, our analysis is limited to October only, we measure a clear distinction at $275 \mathrm{hPa}$ between the two separate regimes with the values in the biomass burning region constantly between 50 and 160 pptv higher than the less polluted South Pacific region. At $180 \mathrm{hPa}$, the same distinction is apparent although less pronounced with differences between 20 and $50 \mathrm{pptv}$. On the 18th October 2003 the average data in the biomass burning region at $180 \mathrm{hPa}$ is comparable to the average over the less polluted South Pacific at $275 \mathrm{hPa}$. Although not shown, we see similiar results in the January and August 2003 data, with 


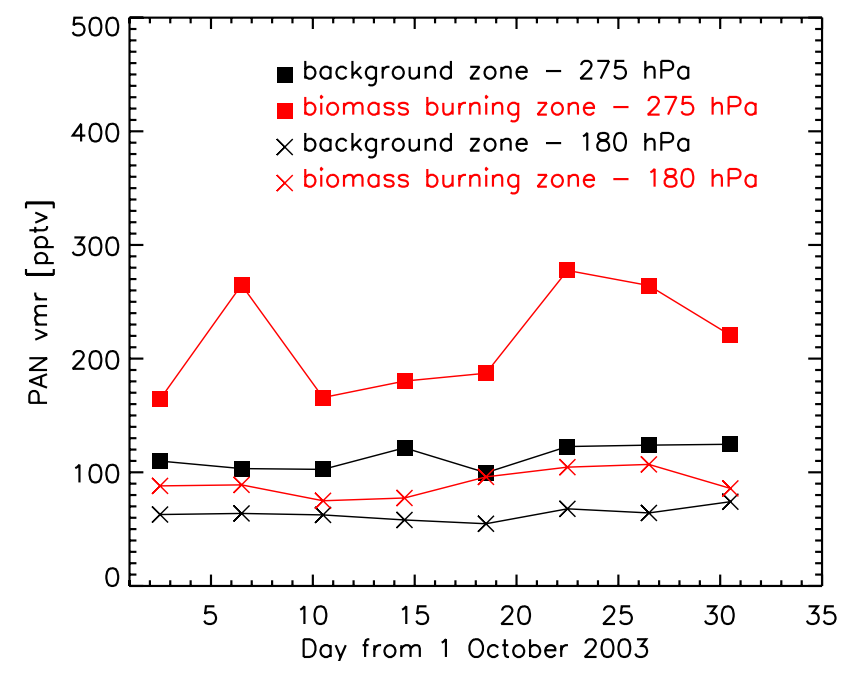

Fig. 11. 4-Daily averages on PAN amounts measured in the region 0 to $30^{\circ} \mathrm{S}, 60^{\circ} \mathrm{W}$ to $135^{\circ} \mathrm{E}$ (biomass burning zone) and 0 to $30^{\circ} \mathrm{S}$, 90 to $180^{\circ} \mathrm{W}$ (South Pacific background zone) for the month of October 2003. The regions were chosen based on those of Glatthor et al. (2007), Fig. 9, for qualitative comparison.

reduced differences as the plume between Southern Africa and Australia is less pronounced in these months suggesting either a shorter lifetime of PAN or less PAN production from the African biomass burning.

\subsection{Qualitative comparison with other measurements}

There are no opportunities for direct comparison in the fullresolution mode data of MIPAS used in this paper. A qualitative comparison can be made with the airborne in-situ data measured by the NASA Global Tropospheric Experiment (GTE) in September/October 1992, a study which investigated the impact of biomass burning over the Southern American and African continents (Singh et al., 1996). During a single flight from Rio de Janeiro to Johannesburg, PAN levels of between 300 and 500 pptv were found in the 10$11 \mathrm{~km}$ altitude range. This compares reasonably well with the average October $2003 \mathrm{PAN} \mathrm{vmr}$ in the region $20^{\circ} \mathrm{S}$ to $40^{\circ} \mathrm{S}, 50^{\circ} \mathrm{W}$ to $30^{\circ} \mathrm{E}$ of $285 \mathrm{pptv}$.

A recent study by Glatthor et al. (2007) used MIPAS-E data to retrieve global PAN vmrs for the autumn and early winter of 2003, over 10 separate days. Their findings (Fig. 7) were similar to ours (Fig. 10) insomuch as the retrieved vmrs demonstrate a weak hemispheric gradient with higher vmrs in the Northern Hemipshere UT and a tropical UT peak in vmrs centred between $20^{\circ} \mathrm{S}$ to $40^{\circ} \mathrm{S}$.

Finally, the work of Remedios et al. (2007a) retrieved PAN amounts of $260 \mathrm{pptv}$ and $180 \mathrm{pptv}$ at altitudes of $7.5 \mathrm{~km}$ and $10.5 \mathrm{~km}$ repectively from MIPAS-B2 data measured over the Mediterranean region in May 1998. From the MIPAS-E data we determine an increase over the Mediterranean from
200 pptv in January 2003 to 350 pptv in August 2003 at $10 \mathrm{~km}$, similar to that observed in the single MIPAS-B2 measurement.

\section{Conclusions}

Peroxyacetyl nitrate is a ubiquitous, odd-nitrogen compound $\left(\mathrm{NO}_{\mathrm{y}}\right)$ present in the upper troposphere and lowermost stratosphere and its importance lies in the fact that it acts as a reservoir of nitrogen oxides $\left(\mathrm{NO}_{\mathrm{x}}=\mathrm{NO}+\mathrm{NO}_{2}\right)$. The long lifetime of PAN at the cold temperatures of the upper troposphere can allow $\mathrm{NO}_{\mathrm{x}}$ to be sequestered and transported until it is released at lower and warmer altitudes, potentially resulting in ozone production in remote regions. Although previous measurements using the MIPAS-E have shown that PAN is present between 8 and $14 \mathrm{~km}$ in the atmosphere, the study was limited to a snapshot of ten days from October to December. In this study, we use data retrieved from the MIPAS-E instrument and analyse the seasonal cycles present in upper tropospheric PAN, extending the study to observe the Northern Hemisphere summertime.

This work has demonstrated the ability of the MORSE scheme to successfully retrieve PAN vmrs from MIPAS-E spectral data between 300 and $150 \mathrm{hPa}$ (approximately 9 to $15 \mathrm{~km}$ in altitude). Based on an error evaluation, it is feasible to identify PAN in individual spectra. From our analysis we find that the error on a single profile retrieval is generally better than $50 \%$ and in most cases lower than $20 \%$ with the major error sources being temperature and pressure with a significant contribution from water vapour in the tropics. Inaccuracies from the spectroscopy are estimated at $4 \%$ on the retrieved vmr datasets. At the coldest tropical tropopause temperatures $(\sim 180 \mathrm{~K})$, we estimate that this error will rise to a maximum of $5.2 \%$.

We have shown that there is a strong seasonality in PAN vmrs in the UTLS, linked with the subtle interannual changes in biomass burning regions. There is also a possible connection with the variability of the growing season which controls the production and release of acetone from plants. The released peroxy radical in the presence of $\mathrm{NO}_{\mathrm{x}}$ initiates the formation of PAN. This is highlighted most strongly in the August 2003 data, towards the centre of the Northern Hemisphere growing season, where PAN vmrs exceed $600 \mathrm{pptv}$ at $278 \mathrm{hPa}$ (around $11 \mathrm{~km}$ ) in the monthly average. Outside the tropics, the Northern Hemisphere PAN values, on average, vary between 300 and $600 \mathrm{pptv}$ compared to the Southern Hemisphere variability of between 100 and 230 pptv.

Our work confirms that current satellite systems are highly suitable for monitoring of PAN vmrs in the upper troposphere and lower stratosphere. There is a strong need to observe organic species such as PAN to begin to answer where the highest vmrs are observed, and to validate model estimates of its lifetime in the UTLS. Future work will likely involve extending the analysis to a multi-year dataset of the MIPAS 
data so we are more clearly able to see the transition between seasons and further understand the role the gas plays in the chemistry of the UTLS. The higher vertical sampling of MIPAS in "optimal-resolution" mode may help to resolve this.

Acknowledgements. David Moore was supported by a research grant from the Natural Environment Research Council. The authors wish to thank the European Space Agency for access to MIPAS data under CUTLSOM (AO.357). The authors would also like to thank Anu Dudhia for providing us with the Oxford reference forward model (RFM) and the MIPAS Orbital Retrieval using Sequential Estimation (MORSE) scheme used in this study.

Edited by: A. Hofzumahaus

\section{References}

Allen, G., Remedios, J. J., Newnham, D. A., Smith, K. M., and Monks, P. S.: Improved mid-infrared cross-sections for peroxyacetyl nitrate (PAN) vapour, Atmos. Chem. Phys., 5, 47-56, doi:10.5194/acp-5-47-2005, 2005a.

Allen, G., The Infrared Remote Sensing of Peroxyacetyl Nitrate in the Upper Troposphere, Ph.D, University of Leicester, UK, 2005b.

Allen, G., Remedios, J. J., and Smith, K. M.: Low temperature midinfrared cross-sections for peroxyacetyl nitrate (PAN) vapour, Atmos. Chem. Phys., 5, 3153-3158, doi:10.5194/acp-5-31532005, 2005c.

Coheur, P.-F., Herbin, H., Clerbaux, C., Hurtmans, D., Wespes, C., Carleer, M., Turquety, S., Rinsland, C. P., Remedios, J., Hauglustaine, D., Boone, C. D., and Bernath, P. F.: ACE-FTS observation of a young biomass burning plume: first reported measurements of $\mathrm{C}_{2} \mathrm{H}_{4}, \mathrm{C}_{3} \mathrm{H}_{6} \mathrm{O}, \mathrm{H}_{2} \mathrm{CO}$ and PAN by infrared occultation from space, Atmos. Chem. Phys., 7, 5437-5446, 2007,

http://www.atmos-chem-phys.net/7/5437/2007/.

Cortesi, U., Lambert, J. C., De Clercq, C., Bianchini, G., Blumenstock, T., Bracher, A., Castelli, E., Catoire, V., Chance, K. V., De Mazire, M., Demoulin, P., Godin-Beekmann, S., Jones, N., Jucks, K., Keim, C., Kerzenmacher, T., Kuellmann, H., Kuttippurath, J., Iarlori, M., Liu, G. Y., Liu, Y., McDermid, I. S., Meijer, Y. J., Mencaraglia, F., Mikuteit, S., Oelhaf, H., Piccolo, C., Pirre, M., Raspollini, P., Ravegnani, F., Reburn, W. J., Redaelli, G., Remedios, J. J., Sembhi, H., Smale, D., Steck, T., Taddei, A., Varotsos, C., Vigouroux, C., Waterfall, A., Wetzel, G., and Wood, S.: Geophysical validation of MIPAS-ENVISAT operational ozone data, Atmos. Chem. Phys., 7, 4807-4867, doi:10.5194/acp-7-4807-2007, 2007.

Crawford, J., Olson, J., Davis, D., Chen, G., Barrick, J., Shetter, R., Lefer, B., Jordan, C., Anderson, B., Clarke, A., Sachse, G., Blake, D., Singh, H., Sandolm, S., Tan, D., Kondo, Y., Avery, M., Flocke, F., Eisele, F., Mauldin, L., Zondlo, M., Brune, W., Harder, H., Martinez, M., Talbot, R., Bandy, A., and Thornton, D.: Clouds and trace gas distributions during TRACE-P, J. Geophys. Res., 108, 8818, doi:10.1029/2002JD003177, 2003.

Edwards, D. P.: GENLN2: A general line-by-line atmospheric transmittance and radiance model, Version 3.0 description and users guide, NCAR/TN-367-STR, National Center for Atmospheric Research, Boulder, CO, USA, 1992.
Fischer, H. and Oelhaf, H.: Remote sensing of vertical profiles of atmospheric trace constituents with MIPAS limb-emission spectrometers, Appl. Optics, 35, 2787-2796, 1996.

Fischer, H., Birk, M., Blom, C., Carli, B., Carlotti, M., von Clarmann, T., Delbouille, L., Dudhia, A., Ehhalt, D., Endemann, M., Flaud, J. M., Gessner, R., Kleinert, A., Koopman, R., Langen, J., López-Puertas, M., Mosner, P., Nett, H., Oelhaf, H., Perron, G., Remedios, J., Ridolfi, M., Stiller, G., and Zander, R.: MIPAS: an instrument for atmospheric and climate research, Atmos. Chem. Phys., 8, 2151-2188, doi:10.5194/acp-8-2151-2008, 2008.

Glatthor, N., von Clarmann, T., Fischer, H., Funke, B., Grabowski, U., Höpfner, M., Kellmann, S., Kiefer, M., Linden, A., Milz, M., Steck, T., and Stiller, G. P.: Global peroxyacetyl nitrate (PAN) retrieval in the upper troposphere from limb emission spectra of the Michelson Interferometer for Passive Atmospheric Sounding (MIPAS), Atmos. Chem. Phys., 7, 2775-2787, doi:10.5194/acp7-2775-2007, 2007.

Hauglustaine, D., Brasseur, G., Walters, S., Rasch, P., Müller,J.F., Emmons, L., and Carroll., M.: MOZART, a global chemical transport model for ozone and related chemical tracers 2. Model results and evaluation, J. Geophys. Res., 103(D21), 2829128335.

Holton, J. R., Haynes, P. H., McIntyre, M. E., Douglass, A. R., Rood, R. B., and Pfister, L.: Stratosphere-troposphere exchange, Rev. Geophys., 33(4), 403-439, 1995.

Jacob, D. J. The oxidising power of the atmosphere, Handbook of Weather, Climate and Water, edited by: Potter, T. D. and Colman, B., Wiley, 29-43, 2003.

Jacob, D. J., Field, B. D., Jin, E. M., Bey, I., Li, Q., Logan, J. A., Yantosca, R. M., and Singh, H. B.: Atmospheric budget of acetone, J. Geophys. Res., 107(D10), 4100, doi:10.1029/2001JD000694, 2002.

Kleinert, A., Aubertin, G., Perron, G., Birk, M., Wagner, G., Hase, F., Nett, H., and Poulin, R.: MIPAS Level 1B algorithms overview: operational processing and characterization, Atmos. Chem. Phys., 7, 1395-1406, doi:10.5194/acp-7-13952007, 2007.

Lahoz, W., Geer, A., Swinbank, R., Jackson, D., Thornton, H., Dethof, A., and Fonteyn, D.: Modelling and assimilation: evaluation of MIPAS water vapour, Proceedings of the ACVE-2 meeting, 3-7 May, Frascati, Italy, 2004.

Min., S. and Wildt, J.: Quantification of acetone emissions from pine plants, Sci. China. Ser. B, 45(5), 532-540, 2002.

Pöschl, U., Williams, J., Hoor, P., Fischer, H., Crutzen, P. J., Warneke, C., Holzinger, R., Hansel, A., Jordan, A., Lindinger, W., Scheeren, H. A., Peters, W., and Lelieveld, J.: High acetone concentrations throughout the $0-12 \mathrm{~km}$ altitude range over the tropical rainforest in Surinam, J. Atmos. Chem., 38(2), 115-132, 2001.

Press, W. H., Flannery, B. P., Teukolsky, S. A., and Vetterling, W. T.: Numerical Recipes in FORTRAN 77: The Art of Scientific Computing, version 1, Cambridge University Press, 28-29, 1992.

Raspollini, P., Belotti, C., Burgess, A., Carli, B., Carlotti, M., Ceccherini, S., Dinelli, B. M., Dudhia, A., Flaud, J.-M., Funke, B., Höpfner, M., López-Puertas, M., Payne, V., Piccolo, C., Remedios, J. J., Ridolfi, M., and Spang, R.: MIPAS level 2 operational analysis, Atmos. Chem. Phys., 6, 5605-5630, doi:10.5194/acp6-5605-2006, 2006.

Remedios, J. J., Allen, G., Waterfall, A. M., Oelhaf, H., Kleinert, 
A., and Moore, D. P.: Detection of organic compound signatures in infra-red, limb emission spectra observed by the MIPASB2 balloon instrument, Atmos. Chem. Phys., 7, 1599-1613, doi:10.5194/acp-7-1599-2007, 2007a.

Remedios, J. J., Leigh, R. J., Waterfall, A. M., Moore, D. P., Sembhi, H., Parkes, I., Greenhough, J., Chipperfield, M. P., and Hauglustaine, D.: MIPAS reference atmospheres and comparisons to V4.61/V4.62 MIPAS level 2 geophysical data sets, Atmos. Chem. Phys. Discuss., 7, 9973-10017, doi:10.5194/acpd7-9973-2007, 2007b.

Ridolfi, M., Blum, U., Carli, B., Catoire, V., Ceccherini, S., Claude, H., De Clercq, C., Fricke, K. H., Friedl-Vallon, F., Iarlori, M., Keckhut, P., Kerridge, B., Lambert, J.-C., Meijer, Y. J., Mona, L., Oelhaf, H., Pappalardo, G., Pirre, M., Rizi, V., Robert, C., Swart, D., von Clarmann, T., Waterfall, A., and Wetzel, G.: Geophysical validation of temperature retrieved by the ESA processor from MIPAS/ENVISAT atmospheric limb-emission measurements, Atmos. Chem. Phys. Discuss., 7, 5439-5513, doi:10.5194/acpd-7-5439-2007, 2007.

Roberts, J. M., Flocke, F., Chen, G., de Gouw, J. A., Holloway, J. S., Hubler, G., Neuman, J. A, Nicks, D. K., Nowak, J. B., Parrish, D. D., Ryerson, T. B., Sueper, D. T., Warneke, C., and Fehsenfeld, F. C.: Measurement of peroxycarboxylic nitric anhydrides (PANs) during the ITCT 2K2 aircraft intensive experiment, J. Geophys. Res., 109, D23S21, doi:10.1029/2004JD004960, 2004.

Rodgers, C.: Inverse methods for atmospheric sounding: theory and practice, World Sci., River Edge, NJ, USA, 1-64, 2000.

Rothman, L. S., Jacquemart, D., Barbe, A., Chris Benner, D., Birk, M., Brown, L. R., Carleer, M. R., Chackerian Jr., C., Chance, K., Coudert, L. H., Dana, V., Devi, V. M., Gamache, R. R., Goldman, A., Jucks, K. W., Maki, A. G., Massie, S. T., Orphal, J., Perrin, A., Rinsland, C. P., Smith, M. A. H., Tennyson, J., Tolchenov, R. N., Toth, R. A., Vander Auwera, J., Varanasi, P., Wagner, G.: The HITRAN 2004 molecular spectroscopic database, J. Quant. Spec. Rad. Trans., 96, 139-204, 2005.

Russo, R. S., Talbot, R. W., Dibb, J. E., Scheuer, E., Seid, G., Jordan, C. E., Fuelberg, H. E., Sachse, G. W., Avery, M. A., Vay, S. A., Blake, D. R., Blake, N. J., Atlas, E., Fried, A., Sandholm, S. T., Tan, D., Singh, H. B., Snow, J., and Heikes, B. G.: Chemical composition of Asian continental outflow over the western Pacific: results from Transport and Chemical Evolution over the Pacific (TRACE-P), J. Geophys. Res, 108(D20), 8804, doi:10.1029/2002JD003184, 2003.
Singh, H. B., Brune, W. H., Crawford, J. H., Flocke, F., and Jacob, D. J.: Chemistry and transport of pollution over the Gulf of Mexico and the Pacific: spring 2006 INTEX-B campaign overview and first results, Atmos. Chem. Phys., 9, 2301-2318, doi:10.5194/acp-9-2301-2009, 2009.

Singh, H. B., Herlth, D., Kolyer, R., Chatfield, R., Viezee, W., Salas, L. J., Chen, Y., Bradshaw, J. D., Sandholm, S. T., Talbot, R., Gregory, G. L., Anderson, B., Sachse, G. W., Browell, E., Bachmeier, A. S., Blake, D. R., Heikes, B., Jacob, D., and Fuelberg, H. E.: Impact of biomass burning emissions on the composition of the South Atlantic troposphere: Reactive nitrogen and ozone, J. Geophys. Res., 101(D19), 24203-24219, 1996.

Singh, H. B. and Hanst, P. L.: Peroxyacetyl nitrate (PAN) in the unpolluted atmosphere: An important reservoir for nitrogen oxides. Geophys. Res. Lett., 8, 941-944, 1981.

Spang, R., Remedios, J. J., Kramer, L. J., Poole, L. R., Fromm, M. D., Müller, M., Baumgarten, G., and Konopka, P.: Polar stratospheric cloud observations by MIPAS on ENVISAT: detection method, validation and analysis of the northern hemisphere winter 2002/2003, Atmos. Chem. Phys., 5, 679-692, doi:10.5194/acp-5-679-2005, 2005.

Spang, R., Remedios, J. J., and Barkley, M. P.: Colour indices for the detection and differentiation of cloud types in infrared limb emission spectra, Adv. Space. Res., 33, 1041-1047, 2004.

Talukdar, R. K., Burkholder, J. B., Schmoltner, A., Roberts, J. M., Wilson, R. R. and Ravishankara, A. R.: Investigation of loss processes for peroxyacetyl nitrate in the atmosphere: UV photolysis and reaction with OH, J. Geophys. Res., 100, 14163-14173, 1995.

Wetzel, G., Bracher, A., Funke, B., Goutail, F., Hendrick, F., Lambert, J.-C., Mikuteit, S., Piccolo, C., Pirre, M., Bazureau, A., Belotti, C., Blumenstock, T., De Maziére, M., Fischer, H., Huret, N., Ionov, D., López-Puertas, M., Maucher, G., Oelhaf, H., Pommereau, J.-P., Ruhnke, R., Sinnhuber, M., Stiller, G., van Roozendael, M., and Zhang, G.: Validation of MIPAS-ENVISAT $\mathrm{NO}_{2}$ operational data, Atmos. Chem. Phys., 7, 3261-3284, 2007, http://www.atmos-chem-phys.net/7/3261/2007/. 